\title{
Heavy Metals in Keana Salt Lake and Some Sources of Drinking Water Within the Keana Salt Lake Community, Nasarawa State, Nigeria
}

\author{
Sule Philip Ivoms Ogah \\ Department of Chemistry, Faculty of Science, Federal University of Lafia, Lafia, Nasarawa State, Nigeria
}

Email address:

suleimanogah@gmail.com

\section{To cite this article:}

Sule Philip Ivoms Ogah. Heavy Metals in Keana Salt Lake and Some Sources of Drinking Water Within the Keana Salt Lake Community, Nasarawa State, Nigeria. Science Journal of Analytical Chemistry. Vol. 8, No. 2, 2020, pp. 56-59. doi: 10.11648/j.sjac.20200802.13

Received: April 2, 2020; Accepted: April 26, 2020; Published: May 14, 2020

\begin{abstract}
Utilization of Salt Lake may portend risk in terms of environmental and human health. The study aimed at analyzing for selected metallic ions in Keana Salt Lake and sources of drinking water in Keana Salt Lake Community, so as to identify and determine the amount of heavy metals in comparison with WHO (World Health Organization) permissible limits. Heavy metals analyzed in the study includes Lead (mg/L), Cadmium (mg/L), Copper (mg/L), Iron (mg/L), Nickel (mg/L), Manganese $(\mathrm{mg} / \mathrm{L})$, Aluminum $(\mathrm{mg} / \mathrm{L})$, Zinc $(\mathrm{mg} / \mathrm{L})$, Cobalt $(\mathrm{mg} / \mathrm{L})$, Arsenic $(\mathrm{mg} / \mathrm{L})$ and Chromium $(\mathrm{mg} / \mathrm{L})$. Atomic absorption spectroscopy (AAS) was used to analyze five samples collected in triplicates from well water (WW), Salt Lake water (SLW) Filtrate from salt lake water (FSLW), non-motorized borehole (BH1) and motorized borehole (BH2) located within Keana community, Nasarawa state, Nigeria. Study findings indicate that while Cobalt was not detected in any of the water samples, mean concentration values for Zinc, Copper and Alumunium were within permissible limits set by WHO. Furthermore, mean concentration values for Manganese, Chromium, Iron, Nickel, Cadmium, Lead and Arsenic exceeded WHO permissible limits. Mean concentration levels of some heavy metals analyzed in the study shows that utilizing water in the study area may be hazardous to environmental health. The study recommends regular treatment of water from the study area before utilization by the populace.
\end{abstract}

Keywords: Heavy Metals, Salt Lake, Mean Concentration Values, AAS, Metallic Ions

\section{Introduction}

Salt lakes despite having high salinity, are fundamental to survival of people who live near them particularly when there are no alternative water sources. Apart from minerals resources (including heavy metals) that may be found in many salt lakebeds, domestic and industrial use of salt lake water which may negatively affect the wellbeing of flora and fauna have been reported [1]. On that note, Heavy metal refers to any metal and metalloid element that has a relatively high density (usually $5 \mathrm{gcm}^{-3}$ or more) with atomic mass above 23 [2]. They are found widely in the earth's crust and are non-biodegradable in nature [3]. Assessment of water samples from seven salt lakes in Romania indicates that Lead $(\mathrm{Pb})$ concentrations were up to $6 \mathrm{mg} / \mathrm{L}$ while Cadmium $(\mathrm{Cd})$ ranged from as low as $0.52 \mathrm{mg} / \mathrm{L}$ to about $1.9 \mathrm{mg} / \mathrm{L} \mathrm{[4]}$. Metal evaluation of samples collected from groundwater wells in the southern Salt lake region, USA shows that chromium, aluminum, nickel, copper and zinc had median concentrations values of $0.002 \mathrm{mg} / \mathrm{L}, 0.002 \mathrm{mg} / \mathrm{L}, 0.003$ $\mathrm{mg} / \mathrm{L}, \quad 0.002 \mathrm{mg} / \mathrm{L}$ and $0.003 \mathrm{mg} / \mathrm{L}$ respectively while cadmium and lead were not detected in the metallic analysis [5]. A comprehensive groundwater quality study which included physicochemical examination of groundwater samples collected from Salt Lake City in India found out that iron mean concentration was $0.8 \mathrm{mg} / \mathrm{L}$ which also exceeded WHO permissible limits [6]. A recent study on chemical composition of salt lake located within east Transbaikalia, Russia found out that mean concentration ranges for aluminum, manganese, cobalt and zinc were $0.002 \mathrm{mg} / \mathrm{L}$ to $0.024 \mathrm{mg} / \mathrm{L}, 0.08 \mu \mathrm{g} / \mathrm{L}$ to $0.16 \mu \mathrm{g} / \mathrm{L}, 0.26 \mu \mathrm{g} / \mathrm{L}$ to $0.38 \mu \mathrm{g} / \mathrm{L}$ and $0.006 \mathrm{mg} / \mathrm{L}$ to $0.038 \mathrm{mg} / \mathrm{L}$ respectively [7]. In another research, analysis of water samples collected from three lakes in Johor Bharu, Malaysia which were evaluated using 
neutron activated analysis (NAA) indicates that Arsenic and Chromium concentrations were within the range of 0.01 $\mathrm{mg} / \mathrm{L}$ to $0.033 \mathrm{mg} / \mathrm{L}$ and $0.018 \mathrm{mg} / \mathrm{L}$ and $0.062 \mathrm{mg} / \mathrm{L}$, respectively [8]. Saline water systems may present risks of heavy metal contamination and consequent poisoning when the lakebed is exposed to heavy metal contaminants. A study conducted around the Great Salt Lake, USA where samples were collected from shorelines of exposed lakebed and analyzed using X-ray fluorescence indicated that arsenic had high concentrations while zinc, iron, manganese, copper and lead were statistically significant in terms of difference in location [9]. Apart from natural occurrences of heavy metals in fresh water systems, human activities especially discharge of untreated effluent may cause ecological as well as health challenges for those that live or work close to salt lake areas. Studies have shown that salt lakes in Ebonyi State, Nigeria, contain metallic ions $[10,11]$. Though a number of studies have looked at water quality in terms of heavy metal characterization and concentration in Nasarawa State [12] and other parts of Nigeria [13-15], literature is lacking assessment of heavy metals in Keana Salt Lake and water supply around Keana Salt Lake area, Nasarawa State Nigeria. Since the concentration levels of these heavy metals in drinking water and food poses great health risks to man [16], there is need to undertake an evaluation of these heavy metals in salt lake water systems and water supply in salt lake community for domestic utilization. Therefore, the study aimed at analyzing the Keana Salt Lake Water and selected sources of drinking water within the Keana salt lake community, so as to identify and determine the amount of heavy metals such as Lead, Cadmium, Copper, Iron, Nickel, Manganese, Aluminum, Zinc, Cobalt, Arsenic and Chromium present in the salt lake and groundwater sources within the study area in comparison with WHO permissible levels.

\section{Materials and Methods}

\subsection{Study Area}

Keana Salt Lake is situated in Keana Local Government Area of Nasarawa State, north central Nigeria. It lies within latitude $8^{\circ} 09^{\prime} 33.0^{\prime \prime} \mathrm{N}$ and longitude $8^{\circ} 47^{\prime} 51.1^{\prime \prime} \mathrm{E}$. Keana is one of the thirteen Local Government Areas of Nasarawa State, Nigeria. The Salt Lake in Keana has served as a source of table salt for people living around the area for decades. There is no modernized industrial setting for processing the salt in the study area; extraction is usually done using traditional methods which is still prevalent today. The local techniques employed by the natives in obtaining the filtrate to be evaporated to get the table salt is worthy of note. The saline water is poured on to a bed of mud from the salt lake which acts as a filter and allowed to stand in an earth ware pot with a tiny opening at the bottom. The clear saline water filtrate is collected in a container placed at the other end of the opening.

\subsection{Sample Collection}

The Water samples were collected from five different water sources in the study area: well water (WW), Salt Lake water (SLW), Filtrate from Salt Lake Water (FSLW), motorized Borehole (BH1) and non motorized borehole (BH2). The sampling was carried out in rainy season in the month of June. Eight plastic containers of a liter capacity each was used in collecting the samples. Each container was washed with detergent, rinsed properly with distilled water and sun dried. The container was rinsed again with the sample water at the point of sample collection and the rinsed water thrown out of the sampling area. Each sample was immediately covered and labeled before preserving them at low temperature of $4^{\circ} \mathrm{C}$ using ice chest.

\subsection{Preparation of Samples for Atomic Absorption Spectroscopy (AAS) Analysis}

The salt water and ground water samples for the cations and anions were filtered using Whatman $0.45 \mu \mathrm{m}$ filter paper into a clean plastic container and acidified with $3 \mathrm{~cm}^{3}$ of concentrated $\mathrm{HNO}_{3}$ per liter of water sample [17] and frozen before analysis to prevent loss of metals by surface adsorption [18]. The samples were analyzed using AAS with respective wavelength of absorption for the metals. The results obtained were subjected to statistical analysis using one-way analysis of variance (ANOVA) on the statistical programme SPSS version 21. Difference was considered significant at $\mathrm{P} \leq 0.05$.

\section{Results and Discussion}

Study results showing the mean values of parameters analyzed are presented in Table 1 . From the results, most of the parameters were significant in terms of ANOVA statistics $(\mathrm{P}<0.05)$ except Copper which was insignificant while Cobalt and lead mean values were not applicable in the analysis. Mean values for Manganese varied between $0.019 \pm 0.000 \mathrm{mg} / \mathrm{L}$ in FSLW and $0.589 \pm 0.023 \mathrm{mg} / \mathrm{L}$ in $\mathrm{BH} 2$. Mean values of Manganese below $0.019 \mathrm{mg} / \mathrm{L}$ have been reported in a Salt Lake in Transbaikalia, Russia [7]. However, all the mean values of manganese were above WHO limits, especially SLW and BH2 with mean values of $0.479 \pm 0.021$ $\mathrm{mg} / \mathrm{L}$ and $0.589 \pm 0.023 \mathrm{mg} / \mathrm{L}$ respectively. The concentration of zinc in the water samples ranged from $1.510 \mathrm{mg} / \mathrm{L}$ (FSLW) to $2.828 \pm 0.034 \mathrm{mg} / \mathrm{L}(\mathrm{BH} 2)$, with all the values below WHO limit for zinc which is $5.000 \mathrm{mg} / \mathrm{L}$. Zinc concentration in the water samples studied are all above those identified in the Salt Lake region of the USA [5]. However, zinc concentrations identified in the water samples studied are significant in terms of location which is in line with what has been reported about zinc concentrations from the Great Salt Lake, USA [9]. Mean value of chromium in the water samples ranged from $0.038 \pm 0.001 \mathrm{mg} / \mathrm{L}$ in FSLW sample to $0.0630 \pm 0.333 \mathrm{mg} / \mathrm{L}$ in $\mathrm{BH} 2$ sample. Chromium values were highest in SLW $(0.054 \pm 0.001 \mathrm{mg} / \mathrm{L})$ and $\mathrm{BH} 2(0.0630 \pm 0.033$ $\mathrm{mg} / \mathrm{L}$ ); both values were above the WHO limit for chromium which is $0.050 \mathrm{mg} / \mathrm{L}$. This is similar to the findings from evaluating water samples collected in Johor Bharu Lake, Malaysia where concentration of chromium was as high as $0.062 \mathrm{mg} / \mathrm{L}$ [8]. 
Table 1 Mean values of heavy metals in the water samples collected from Keana Salt Lake Community and the Salt Lake water.

\begin{tabular}{|c|c|c|c|c|c|c|c|}
\hline Parameter $(\mathrm{mg} / \mathrm{L})$ & WHO limits & FSLW & SLW & WW & BH1 & BH2 & $P$ value \\
\hline Manganese & 0.100 & $0.019 \pm 0.000$ & $0.479 \pm 0.021$ & $0.019 \pm 0.000$ & $0.320 \pm 0.000$ & $0.589 \pm 0.023$ & .000 \\
\hline Cobalt & NS & ND & ND & ND & ND & ND & - \\
\hline Zinc & 5.000 & $1.510 \pm 0.000$ & $2.108 \pm 0.000$ & $1.266 \pm 0.000$ & $2.064 \pm 0.000$ & $2.828 \pm 0.034$ & .000 \\
\hline Chromium & 0.050 & $0.038 \pm 0.001$ & $0.054 \pm 0.001$ & $0.042 \pm 0.000$ & $0.051 \pm 0.000$ & $0.063 \pm 0.000$ & .000 \\
\hline Copper & 1.000 & $0.040 \pm 0.000$ & $0.630 \pm 0.333$ & $0.040 \pm 0.001$ & $0.125 \pm 0.001$ & $0.716 \pm 0.333$ & .107 \\
\hline Iron & 0.300 & $0.517 \pm 0.000$ & $1.241 \pm 0.000$ & $0.413 \pm 0.000$ & $0.828 \pm 0.001$ & $1.448 \pm 0.000$ & .000 \\
\hline Nickel & 0.070 & $0.197 \pm 0.001$ & $0.400 \pm 0.000$ & $0.199 \pm 0.000$ & $0.202 \pm 0.000$ & $0.800 \pm 0.000$ & .000 \\
\hline Aluminium & 0.200 & ND & ND & ND & ND & $0.167 \pm 0.000$ & .000 \\
\hline Cadmium & 0.003 & $0.025 \pm 0.001$ & $0.060 \pm 0.000$ & $0.064 \pm 0.000$ & $0.066 \pm 0.000$ & $0.077 \pm 0.001$ & .000 \\
\hline Lead & 0.010 & $0.506 \pm 0.000$ & $0.753 \pm 0.000$ & $0.630 \pm 0.000$ & $0.877 \pm 0.000$ & $1.000 \pm 0.000$ & - \\
\hline Arsenic & 0.010 & $0.035 \pm 0.000$ & $0.048 \pm 0.000$ & $0.035 \pm 0.000$ & $0.057 \pm 0.000$ & $0.064 \pm 0.000$ & .000 \\
\hline
\end{tabular}

Key: $+=$ Objectionable; - = Unobjectionable; NS = Not Stated; ND = Not Detected

Mean values of Copper in the salt water samples collected ranged from $0.040 \mathrm{mg} / \mathrm{L}$ (FSLW) to $0.716 \pm 0.333 \mathrm{mg} / \mathrm{L}$ (BH2), indicating that none of the sampled locations had copper concentration levels above $1.000 \mathrm{mg} / \mathrm{L}$ which is the WHO limit. Copper concentration levels in water samples collected from southern Salt Lake region, USA were even lower than the least copper concentrations in Keana Salt Lake samples with the value $0.002 \mathrm{mg} / \mathrm{L}$ [5]. However, copper concentrations in Keana Salt Lake water samples were statistically insignificant in terms of location $(p=0.107)$ while copper concentrations in water samples from the Great Salt Lake, USA were significant in terms of location [9]. Mean values of iron in all the five water samples studied (Table 1) were above WHO limit of $0.300 \mathrm{mg} / \mathrm{L}$ and were significant with respect to statistical difference in location $(\mathrm{p}$ $<0.05$ ). Similar findings were made in India where mean concentration of iron in groundwater samples from Salt Lake, West Bengal India were above WHO limit at $0.800 \mathrm{mg} / \mathrm{L}$ [1]. Study results on mean concentration values of Nickel in the five water samples shows that FSLW had the lowest value at $0.197 \pm 0.001 \mathrm{mg} / \mathrm{L}$ while $\mathrm{BH} 2$ had the highest value at 0.800 $\mathrm{mg} / \mathrm{L}$ with all the samples having mean concentrations values above the WHO permissible limit of $0.070 \mathrm{mg} / \mathrm{L}$. Nickel mean concentration value in groundwater samples from the Salt lake region, USA was $0.003 \mathrm{mg} / \mathrm{L}$ which is below the WHO limit [5]. Higher concentration of nickel in water samples from Keana lake may be attributed to geological and geographical phenomenon since there is no visible industrial activities within the community other than the local table salt extraction from the Lake water which may pose pernicious health risk for those who depend on the salt lake and such water source for various water needs [10-12]. Cadmium was detected in all the five water samples with mean concentration values ranging from $0.025 \pm 0.001 \mathrm{mg} / \mathrm{L}$ in FSLW to $0.077 \pm 0.001 \mathrm{mg} / \mathrm{L}$ in $\mathrm{BH} 2$ which exceeded $\mathrm{WHO}$ limit in all the samples. Cadmium concentration values were also statistically significant $(\mathrm{p}<0.05)$ in terms of location. Assessment of salt lakes in Romania gave a maximum cadmium concentration level of $1.9 \mathrm{mg} / \mathrm{L}$ [4] which exceeded WHO limits and is far higher than the levels identified in Keana Salt Lake. Mean concentration values of lead were all well-above WHO limits; values ranged from $0.506 \pm 0.000$ $\mathrm{mg} / \mathrm{L}$ in FSLW to as high as $1.000 \pm 0.000 \mathrm{mg} / \mathrm{L}$ in $\mathrm{BH} 2$ indicating that lead poisoning may pose a significant danger for those who continually depend on water from Keana Salt Lake community or even those depending on the edible salt from the Lake. Higher lead concentrations were reported from an assessment of seven salt lakes in Romania where mean values of up to $6 \mathrm{mg} / \mathrm{L}$ were recorded for Lead in the salt lakes sampled in the study [4]. In terms of Arsenic concentrations in water samples from Keana Salt Lake community, mean values ranging from $0.035 \pm 0.000 \mathrm{mg} / \mathrm{L}$ to $0.064 \pm 0.000 \mathrm{mg} / \mathrm{L}$ were determined; these values were also statistically significant with respect to location of water sample ( $p$ <0.05). Furthermore, all Arsenic mean concentration values in the water samples studied exceeded WHO limit, indicating significant Arsenic levels in water from Keana Salt Lake community. These results agree with findings from the analysis of Johor Bharu lakes, Malaysia where Arsenic concentrations also exceeded WHO limit with concentrations of up to $0.033 \mathrm{mg} / \mathrm{L}$ in some of the water samples studied [8]. Cobalt was not detected in any of the water samples while aluminum was detected in only one of the five areas sampled though still within the WHO limit; a mean concentration value of $0.167 \pm 0.000 \mathrm{mg} / \mathrm{L}$ for $\mathrm{BH} 2$ which was also statistically significant. The result shows that the process of filtration though crude may have very positive effect in reducing heavy metal concentration of the resulting table salt, (FSLW compared to SLW). This reduction could be due to adsorption of the metals on the clay-like mud.

\section{Conclusion}

The Analysis for heavy metal concentration in water samples from Keana Salt Lake and drinking water sources within the lake community has given information on the water quality in terms of their metallic contents. The results indicate that seven out of the ten heavy metals examined in the water samples (Manganese, Chromium, Iron, Nickel, Cadmium, Lead and Arsenic) were above WHO limits. Interestingly the filtration process reduced the metal concentration levels. On the other hands, Zinc, Copper and Aluminum concentrations in the water samples studied were below WHO permissible limits, while Cobalt was not detected in any of the samples. 
Mean concentrations of Lead, Cadmium and Arsenic in all the water samples studied were above WHO limits showing that water quality in Keana Salt Lake area may be unsuitable for human consumption. This is because excessive and continuous intake of these heavy metals through the water medium may have hazardous consequences for those who depend on that medium in terms of their water needs due to accumulation of the metals over time. Therefore, it is important that water from Keana Salt Lake undergo regular treatment before utilization by the populace to prevent the likelihood of physiological interactions with these heavy metals which are pernicious to human health when they exceed permissible limits. In addition, awareness creation should be undertaken to enlighten residents of the study area on the health implications of utilizing untreated water.

\section{Acknowledgements}

I wish to acknowledge my Post graduate students most especially Onwukwe Friday for their supportive roles during this research work.

\section{References}

[1] Banerji, S, \& Mitra, D. (2017). Grey water footprint of domestic households in Salt Lake City, India: An overview. 1527.

[2] Koller, M. and Saleh, H. M. (2018). Introductory Chapter: Introducing Heavy Metals. In Heavy Metals. https://doi.org/10.5772/intechopen.74783

[3] S. K. Sharma. Heavy Metals in Water: Presence, Removal and Safety, Vol. 59, Issue 4. Cambridge: Royal Society of Chemistry, 2015. https://doi.org/10.1595/205651315x689009

[4] Radulescu, C. et al. (2014). Determination of heavy metal levels in water and therapeutic mud by atomic absorption spectrometry. Romanian Journal of Physics 59 (9-10): 1057-1066.

[5] Thiros, S. A. (2003). Quality and sources of shallow ground water in areas of recent residential development in Salt Lake Valley, Salt Lake County, Utah. [online] http://pubs.water.usgs.gov/wri034028

[6] Banerji, S. and Mitra, D. (2017). Evaluation of water resource management in Salt Lake City, West Bengal, India. Hydrological Sciences Journal 62 (12): 1980-1994. https://doi.org/10.1080/02626667.2017.1351028

[7] Borzenko, S. V. and Shvartsev, S. L. (2019). Chemical composition of salt lakes in East Transbaikalia (Russia). Applied Geochemistry 103: 72-84. https://doi.org/10.1016/j.apgeochem.2019.02.014
[8] Salim, N. A. A. et al. (2009). A study of arsenic and chromium contamination in sediments of freshwater bodies. Fresenius Environmental Bulletin 18 (9): 1618-1623.

[9] Thorsen, M. L., Handy, R. G., Sleeth, D. K., Thiese, M. S. and Riches, N. O. (2017). A comparison study between previous and current shoreline concentrations of heavy metals at the Great Salt Lake using portable X-ray fluorescence analysis. Human and Ecological Risk Assessment 23 (8): 1941-1954. https://doi.org/10.1080/10807039.2017.1349541

[10] Agbafor, K. N., Ajah, P. M., Offor, C. E., Igwenyi, I. O. and Ibiam, U. A. (2011). Examination of cardiovascular toxicity and trace elements status in albino rats Treated with Okposi and Uburu salt lakes (Nigeria). Research Journal of Environmental Toxicology, 5 (3): 229-234.

https://doi.org/10.3923/rjet.2011.229.234

[11] Ogbanshi, M. E. et al. (2015). Administration of water and salt samples from Okposi and Uburu Nigerian Salt Lakes induce Oxidative stress in the reproductive parameters of adult male Sprague-Dawley rats. Global Journal of Pharmacology 9 (4): 345-351. https://doi.org/10.5829/idosi.gjp.2015.9.4.10152.

[12] Tukura, B. W. (2013). Preliminary Assessment of Physicochemical Properties of Borehole Water in the vicinity of Public Health Facilities in Nasarawa State, Nigeria. IOSR Journal of Applied Chemistry, 5 (6), 55-63. https://doi.org/10.9790/5736-0565563

[13] Onunkwo, A. A., Nwagbara, J. O. and Ahiarakwem,.C.A. (2014). Assessment of Heavy Metals in Nnewi under Ground Water. International Journal of Engineering Research and Development, $10 \quad$ (11): 01-05. http://ijerd.com/paper/vol10-issue11/Version_2/A10110105.pd $\mathrm{f} \% 5 \mathrm{Cn}$

[14] Adeyemi, O., Oloyede, O. B. and Oladiji, A. T. (2007). Physicochemical and Microbial Characteristics of Leachate-Contaminated Groundwater. Asian Journal of Biochemistry, 2 (5): 343-348. https://doi.org/10.3923/ajb.2007.343.348

[15] Bernard, E. and Ayeni, N. (2012). Physicochemical Analysis of Groundwater Samples of Bichi Local Government Area of Kano State of Nigeria. World Environment 2 (6): 116-119. https://doi.org/10.5923/j.env.20120206.02

[16] Lar, A. U. (2013). Trace Elements and Health: An Environmental Risk in Nigeria. Earth Sciences, 2 (3): 66. https://doi.org/10.11648/j.earth.20130203.11

[17] Ramos, L., Fernández, M. A., González, M. J. and Hernández, L. M. (1999). Heavy metal pollution in water, sediments, and earthworms from the Ebro River, Spain. Bulletin of Environmental Contamination and Toxicology 63 (3): 305-311. https://doi.org/10.1007/s001289900981

[18] Elijah, A. A. (2014). Physico-chemical Analysis of Some Selected Water Sources Around the Waste Treatment Plant of Ahmadu Bello University Teaching Hospital Zaria, Nigeria. MSc Thesis: Ahmadu Bello University, Zaria. 